\title{
Resistance to Change- A New Perspective: A Textbook for Managers Who Plan to Implement a Change
}

\section{Daniela Bradutanu*}

Faculty of Economics and Business Administration, West University of Timisoara, Romania

\section{Introduction}

"Resistance to change- A new perspective. A textbook for Managers who plan to implement a change" is an academic book and presents resistance to change from a new angle. If for many decades resistance was considered only as a bad phenomenon, through the present book, Daniela Bradutanu highlights its positive side too, bringing solid arguments and evidence from other specialists in the field to sustain her affirmations.

The contribution of this book for the management literature is very valuable, as in order to implement a successful change, managers must use resistance to their advantage. As the author states, "resistance is not necessarily negative, and if used appropriately, change agents can actually gain from it".

"The term "resistance" is complex and very often misinterpreted. Change leaders should adapt their perspectives on this subject and try to see resistance from a positive angle as well. By just changing the prospect of analyzing it, managers could experience a greater success in implementing new changes and effectively attract more employees onto their side".

That's a very good point and definitively a true one. If employees are communicated what is happening in the organization and are involved in its processes, their resistance will be very low or even absent. Managers should understand that not all employees' actions represent resistance and sometimes, their behavior might be misinterpreted.

"The ultimate goal is to implement a new change with minimum opposition, focusing on preventing the phenomenon's appearance rather than defeating an already expressed resistance. Thus, for a successful implementation, the change agent first must identify the main reasons that generate employees' resistance and only after this work has been done, can the agent proceed to overcome it".

Of course, each employee will respond to a change differently, depending on his own reasons. It is well know that employees' interests always come first and there will always be people who have had bad experiences in the past and are more cautious. As the author states, the role of the change agent/ manager is to identify the main reasons that determine employees to oppose and then to apply the appropriate $\operatorname{method}(\mathrm{s})$ to reduce their resistance to change.

The model of the forces that generate resistance to change within an organization is very interesting. The author focused and highlighted both the internal factors that can generate resistance to change, as well as the external. The model is well designed, accurate and meets an organization's reality. A model's strength is that it included the "change agent" in the category of the forces that might generate resistance to change, the brought arguments being very solid.

"The change agent can represent a force that contributes to the increase of the resistance to change phenomenon when the need for change is communicated inappropriately. The actions through which the change agent can increase employees' resistance are through failing to justify the need for change, misrepresenting the change outcomes or by the inability to engage in the process all of the affected members of the organization." Also, in order "to convince employees to participate in a change process or simply to "look good", the change agent can intentionally distort the information".

All the presented elements are very important and the author presented clearly the impact of a chosen element on the resistance to change phenomenon. For example: an organization with a culture that focuses on innovation cannot afford hiring people with a rigid mentality and who do not like changes, as the result would be devastating. Their resistance to any change would be very high and they could not face the continuous challenges. In conclusion, depending on company's culture, the management should adjust its personnel policy and hire only employees who share the same values as the ones that form the organization's culture.

Additional to the employees and stakeholders, the change agent, organizational culture, organizational structure, management style, personnel policy and information system, the economic environment plays an important role. Dr. Bradutanu clearly presented the impact that this external force can have on the resistance to change phenomenon and depending on economy's state: a fast growing economy or one in recession, employees' resistance will be high or much reduced.

An original contribution to the literature is the proposed Reducing Resistance to Change Model. As the author states, "The proposed model is recommended when the manager or the change agent reaches the reducing resistance to change stage within an organizational change model. Depending on the position of the resistance to change stage, which is determined by the type of change that follows the implementation, the application of the model may occur before, during, or after the actual implementation of the change".

Overall, the book has a relevant topic and addresses very well the needs of a company. The subject is current and many managers can benefit from reading it. Author's contribution to the management literature is very consistent and important, and it is a great textbook for everyone who plans to implement a change.

Understanding people's attitudes towards a change, knowing how to transform them from change opponents into change supporters is essential if a successful implementation is desired. Additionally, this book describes the necessary actions that managers need to undertake in order to gain employee's support and the things they need to pay attention at if they want to implement successfully a change.

*Corresponding author: Daniela Bradutanu, Faculty of Economics and Business Administration, West University of Timisoara, Romania, Tel: +40 256592 111; E-mail: dbradutanu@gmail.com

Received September 02, 2015; Accepted September 21, 2015; Published September 28, 2015

Citation: Bradutanu D (2015) Resistance to Change- A New Perspective: A Textbook for Managers Who Plan to Implement a Change. Bus Eco J 6: 186. doi:10.4172/2151-6219.1000186

Copyright: @ 2015 Bradutanu D. This is an open-access article distributed unde the terms of the Creative Commons Attribution License, which permits unrestricted use, distribution, and reproduction in any medium, provided the original author and source are credited. 